\title{
Thermodynamic properties and moisture sorption isotherms of two pharmaceutical compounds
}

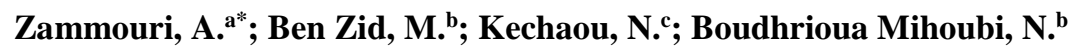 \\ ${ }^{a}$ Laboratoire de Biotechnologie et Valorisation des Bio-Géo Ressources, LR11ES31. Institut Supérieur \\ de Biotechnologie de Sidi Thabet, Univ. Manouba, BP-66, 2020 Ariana-Tunis, Tunisie, Tel: \\ +21671537040; Fax: +21671537044. \\ b Laboratoire de Physiopathologies, Alimentation et Biomolécules, LR17ES03. Institut \\ Supérieur de Biotechnologie de Sidi Thabet, Univ. Manouba, BP-66, 2020 Ariana-Tunis, \\ Tunisie, Tel: +21671537040; Fax: +21671537044. \\ c Groupe de Recherche en Génie des Procédés Agroalimentaires, Ecole Nationale \\ d’Ingénieurs de Sfax, Université de Sfax, BP 1173 3038, Sfax, Tunisie. \\ * E-mail of the corresponding author : amel.zammouri@gmail.com
}

\begin{abstract}
This investigation examines and compares the water sorption isotherms and the thermodynamic properties of two pharmaceutical preparations (Hypril and Azix) intended to be manufactured with the same process plant and equipment. The moisture equilibrium isotherms were determined at 50, 60 and $70^{\circ} \mathrm{C}$ using a gravimetric technique. Five isotherm models were explored for their fitting to the experimental data. Azix showed sigmoid type II isotherms while Hypril showed type III isotherms according to the BET classification. All investigated models fitted well the water sorption isotherms of Hypril. By contrast, only GAB and Adam and Shove equations gave appropriate fit to the experimental data of Azix. For both formulations, the isosteric heat and the differential entropy decreased sharply with the increase of equilibrium moisture content to minimum values and thereafter remain constant. In the case of Azix, the integral enthalpy decreased with equilibrium moisture content while the integral entropy increased until reaching a constant value. Contrariwise, Hypril showed decreasing of the integral enthalpy and entropy with the equilibrium moisture content.
\end{abstract}

Keywords: sorption isotherm, enthalpy, entropy, spreading pressure, pharmaceutical formulations 


\section{Introduction}

Tablets are the most popular advantageous drug dosage form used today. They ensure best protection to the drug against temperature, humidity, oxygen, light and stress during transportation. They present also the best-combined properties of chemical, mechanical and microbiological stability of all the oral form. The manufacture of tablets involved several steps: mixing of therapeutic agents with exipients, granulation of the mixed powders, mixing the obtained granules with other excipients such as lubricants and finally compression into tablets. Wet granulation is a widely applied process in the pharmaceutical industry used to improve powder flow characteristics thereby enhancing the compressibility of the drug. In a typical wet granulation, the water is initially added to the mixed powders to form large agglomerates which will be dehydrated in order to remove water. The drying operation is a crucial step, usually accomplished in fluid-bed dryers, whereby a warmed and low humidity air passed through the agglomerates via a gill plate. Water interacts with pharmaceutical solids not only at this level but also at all stages of manufacture. Therefore, water-powder interaction is a major factor in the formulation, processing, and performance of solid dosage forms. Determination of sorption isotherms of pharmaceutical preparations and deduced thermodynamic properties allows the control of corresponding drying process and modeling of their drying kinetics.

\section{Material and Methods}

Azix (Azithromycine- 500 mg, Anhydrous Dibasic Calcium Phosphate, Pregelatinised starch, Sodium starch glycolate, Magnesium stearate) and Hypril (Enalapril maleate-20 mg, Hydrochlorothiazid -12, 5 mg, Sodium bicarbonate, Lactose Monohydrate, Maize starch, Microcrystalline cellulose, Sodium starch glycolate, Magnesium stearate) preparations are provided from Pharmaghreb ${ }^{\circledR}$ company (Tunisia).

\subsection{Determination of sorption isotherms}

The experimental sorption isotherms of Azix and Hypril preparations were established using the static gravimetric method. The experimental setup consisted of 11 air-sealed glass jars provided with perforated supports in which triplicate samples weighing $0.1 \mathrm{~g}( \pm 0.0001 \mathrm{~g})$ were exposed to the humid atmospheres. Sulfuric acid solutions of known concentration were used to reach 0.06 to 0.95 water activity values. The prepared glass jars were then placed in temperature controlled cabinets maintained at 50, 60 and $70{ }^{\circ} \mathrm{C} \pm 1 \mathrm{C}$. Each sample was weighed at the beginning of experiment and at intervals of $24 \mathrm{~h}$ until constant mass was reached. The equilibrium moisture content was determined according to the AOAC official method [1]. 


\subsection{Sorption models and statistical analyses}

The equilibrium moisture data were fitted with five mathematical models shown in Table 1. The nonlinear regression analysis (MATLAB ${ }^{\circledR}$ ) was used to estimate the constants of the models from the experimental results. To evaluate the goodness of fit of each equation, the coefficient of determination $\mathrm{R}^{2}$, the adjusted $\mathrm{R}^{2}$, the roots mean squared error (RMSE) and the sum of squares due to error (SSE) were determined by using the following equations [2] (Eqs 1 to 6):

The coefficient of determination $R^{2}$ measures the model adequacy, $\left(0 \leq R^{2} \leq 1\right)$ :

$$
R^{2}=\frac{\text { explained variation of } y}{\text { total variation of } y}=\frac{S S R}{S S T}
$$

SSR is the regression sum of squares which reflects the amount of variation in y explained by the model:

$$
S S R=\sum_{i=1}^{n}\left(\widehat{y}_{l}-\bar{y}\right)^{2}
$$

SST is the total sum of squares:

$$
S S T=\sum_{i=1}^{n}\left(y_{i}-\bar{y}\right)^{2}
$$

Where $y_{i}$ is the equilibrium moisture content at observation $i, \bar{y}$ is the mean value of $y_{i}$ of the $\mathrm{n}$ observations and $\hat{y}_{\mathrm{i}}$ is the value of y estimated from the regression model for observation i.

The corrected or adjusted $\overline{\mathrm{R}}^{2}$ :

$$
\bar{R}^{2}=1-\left(1-R^{2}\right) \frac{(n-1)}{(n-k)}
$$

Where $\mathrm{n}$ is the total number of observations and $\mathrm{k}$ is the number of model parameters.

$$
R M S E=\left(\frac{S S E}{n-k}\right)^{1 / 2}
$$

Where SSE is the error sum of squares or sum of the residuals which reflects the variation about the regression line:

$$
S S E=\sum_{i=1}^{n}\left(y_{i}-\widehat{y_{l}}\right)^{2}
$$

\subsection{Calculation of thermodynamic properties}

The net isosteric heat (net enthalpy) of sorption $\left(\mathrm{q}_{\mathrm{st}}\right)$ was obtained from the moisture sorption data using the Clausius-Clapeyron equation [3] :

$$
\frac{d\left(\ln a_{w}\right)}{d\left(\frac{1}{T}\right)}=-\left(\frac{q_{s t}}{R}\right)
$$

In which $q_{s t}=Q_{s}-\Delta H_{v a p}$ where $\mathrm{a}_{\mathrm{w}}$ is the water activity, $\mathrm{q}_{\mathrm{st}}$ is the net isosteric heat of sorption $\left(\mathrm{kJ} \mathrm{mol}^{-1}\right), \mathrm{Q}_{\mathrm{st}}$ is the isosteric heat of sorption $\left(\mathrm{kJ} \mathrm{mol}^{-1}\right), \Delta \mathrm{H}_{\mathrm{vap}}$ is the heat of 
vaporisation ( $\mathrm{kJ} \mathrm{mol}^{-1}$ water), $\mathrm{R}$ is the universal gas constant $\left(8.314 \mathrm{~J} \mathrm{~mol}^{-1} \mathrm{~K}^{-1}\right)$ and $\mathrm{T}$ is the absolute temperature $(\mathrm{K})$. The value of $\mathrm{q}_{\mathrm{st}}$ was calculated from the slope of the plot between values of $\ln \left(\mathrm{a}_{\mathrm{w}}\right)$ and $1 / \mathrm{T}$ at constant moisture content. The differential entropy $\left(\mathrm{S}_{\mathrm{d}}\right)$ of sorption can be calculated from Gibbs-Helmholtz equation as follows:

$$
\mathrm{S}_{\mathrm{d}}=\frac{\mathrm{q}_{\mathrm{st}}-\mathrm{G}}{\mathrm{T}}
$$

Where $G$ is the Free Gibbs energy calculated as:

$$
\mathrm{G}=\mathrm{RT} \ln \left(\mathrm{a}_{\mathrm{w}}\right)
$$

Substituting Eq. (9) into Eq. (8), and after rearranging, the final form is :

$$
-\left.\ln \left(\mathrm{a}_{\mathrm{w}}\right)\right|_{\mathrm{w}}=\frac{-\mathrm{q}_{\mathrm{st}}}{\mathrm{RT}}+\frac{\mathrm{s}_{\mathrm{d}}}{\mathrm{R}}
$$

By plotting $\ln \left(\mathrm{a}_{\mathrm{w}}\right)$ versus $1 / \mathrm{T}$, for a constant moisture content $(\mathrm{W})$, the $S_{d}$ can be determined from the intercept $\left(S_{d} / R\right)$. The $S_{d}$ values at different moisture contents are found from the determination of the relation between $S_{d}$ and moisture content. The net integral enthalpy, $q_{\text {eq }}$ is an integral molar quantity and is calculated in a similar manner to the isosteric heat of sorption but at constant spreading pressure instead of constant moisture content .

$$
\mathrm{q}_{\text {eq }}=-\mathrm{R}\left[\frac{\mathrm{d}\left(\operatorname{lna}_{\mathrm{w}}\right)}{\mathrm{d}(1 / \mathrm{T})}\right]_{\phi}
$$

$\ln (\mathrm{aw})$ was plotted against $1 / \mathrm{T}$ at constant spreading pressure. The net integral enthalpy was determined from the slope of the straight line and plotted against moisture content. The net integral entropy of sorbed water, $\Delta \mathrm{S}_{\mathrm{eq}}$, is given as:

$$
\Delta \mathrm{S}_{\mathrm{eq}}=-\mathrm{q}_{\mathrm{eq}} / \mathrm{T}-\mathrm{R} \ln \left(\mathrm{a}_{\mathrm{w}}\right)^{*}
$$

$\left(a_{w}\right) *$ is the geometric mean water activity obtained at different temperatures and at constant spreading pressures.

\section{Results and Discussion}

\subsection{Water sorption isotherms}

The moisture sorption isotherms of Azix and Hypril at different temperatures are displayed in Fig. 1.

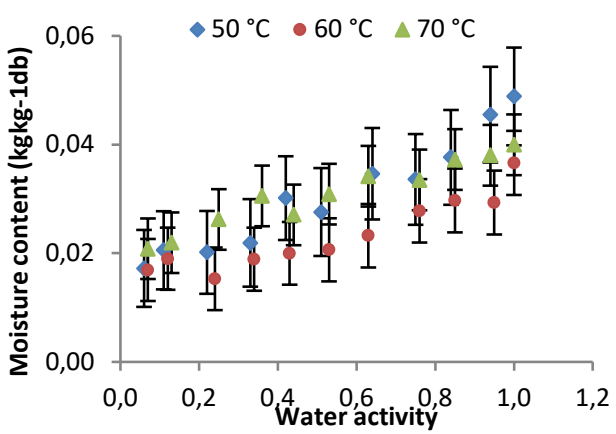

Fig. 1a Experimental moisture sorption isotherms of Azix at $50^{\circ} \mathrm{C}, 60^{\circ} \mathrm{C}, 70^{\circ} \mathrm{C}$

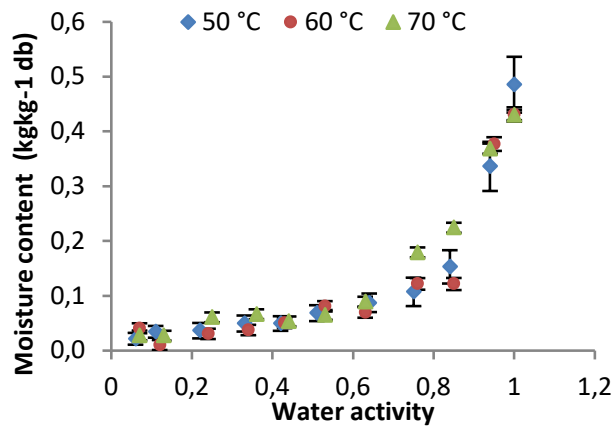

Fig. $1 b$ Experimental moisture sorption isotherms of Hypril at $50^{\circ} \mathrm{C}, 60^{\circ} \mathrm{C}, 70^{\circ} \mathrm{C}$ 
The moisture sorption isotherms of Azix showed moisture levels from 1.5\% to approximately $5 \%$ over water activity range from 0.06 to 0.95 at the examined temperatures (Fig 1.a). These findings are in line with those of [4] who reported the same trend for spray- dried pure azithromycin, the active ingredient of Azix preparation. Indeed, the moisture behavior of pure azithromycin determined using a dynamic vapour sorption system showed $6 \%$ of water absorbed at relative humidity of $90 \%$. Hypril exhibited the same moisture levels as Azix over water activity range from 0.06 to 0.44 . Thereafter, the level of adsorbed water increased sharply from $7 \%$ to approximately $50 \%$ (Fig1.b) . This behavior could be ascribed to the degradation of Enalapril maleate in the presence of lactose and magnesium stearate at very high humidities and temperatures. Enalapril maleate powder is stable under moderate heat and humidity $\left(40^{\circ} \mathrm{C}-75 \% \mathrm{RH}\right)$ [5]. However, when it is prepared in tablet formulations by wet granulation with lactose, starch and magnesium stearate enalapril maleate would degrade to form a diketopiperazine by dehydration and the diacid by hydrolysis. These degradates increase with temperature.

Inspection of Fig. 1a and Fig. 1b indicates that there is no significant effect of temperature on the sorption isotherms of Azix and Hypril formulations. The same behavior was observed on the moisture isotherms of crystalline, amorphous and predominantly crystalline lactose powders established at $12,20,30$ and $40{ }^{\circ} \mathrm{C}$ [6].

\subsection{Mathematical modelling}

The results of nonlinear fitting of sorption models are shown in Table 1 . All the examined models provided a good description of the isotherms of Hypril, the optimal one is the Oswin model which presented the most suitable fitting. As to Azix formulation, only GAB and Adam and Shove models gave appropriate fit between the experimental and the predicted data. 
Table 1.Estimated parameters of the different models fitted to the sorption data for Azix and Hypril

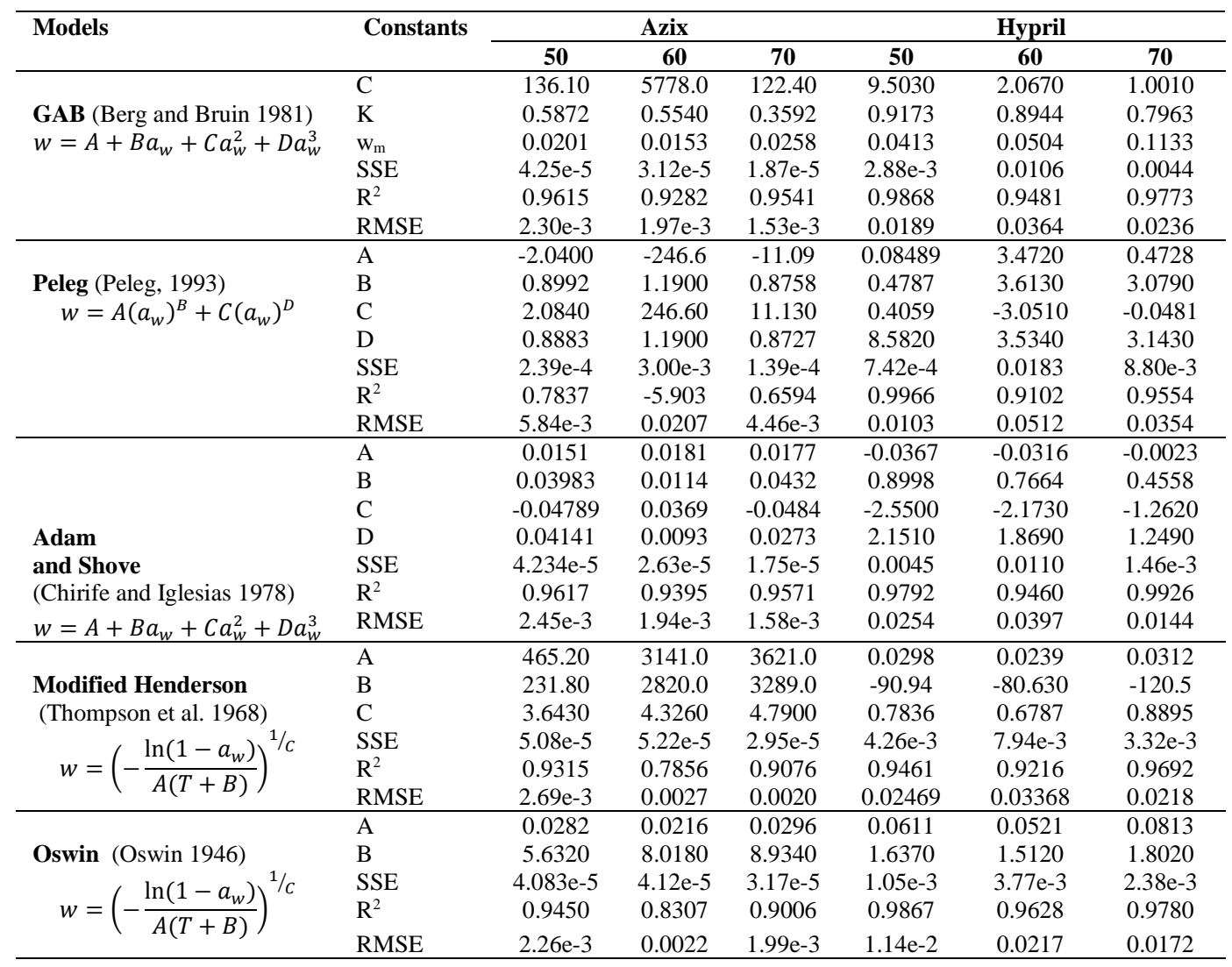

\subsection{Isosteric heat of sorption and sorption entropy}

The results in Fig. 2 illustrate a progressive decrease in the net isosteric heat of sorption (net enthalpy) with increasing moisture content for both formulations. The values of net isosteric heat of sorption are high for equilibrium moisture content $<0.10 \mathrm{~kg} / \mathrm{kg}$ and then decreased rapidly until equilibrium moisture contents reach respective values of 0.15 and $2 \mathrm{~kg} / \mathrm{kg}$ d.b for Azix and Hypril, and then they decreased smoothly with increasing moisture content. Azix showed higher values of net isosteric heat than Hypril. This suggests that the energy to be supplied to dehydrate Azix would be higher than the energy needed to dehydrate Hypril. The differential entropy as a function of moisture content, illustrated by Fig. 3, shows the same tendency as the net isosteric heat. The sorption entropy of Azix exhibited higher magnitude than that of Hypril. 


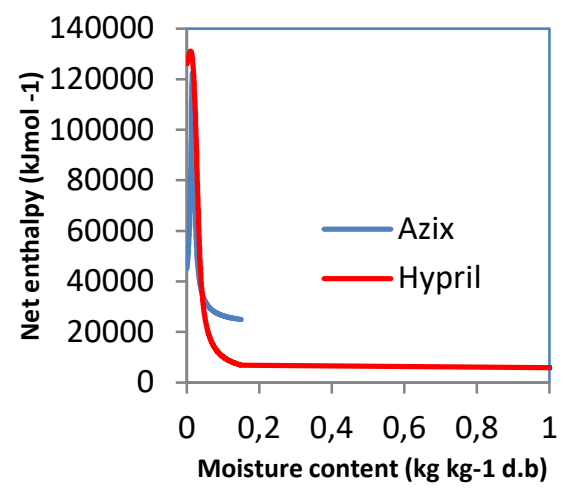

Fig. 2a Net isosteric heat of Azix and Hypril formulations

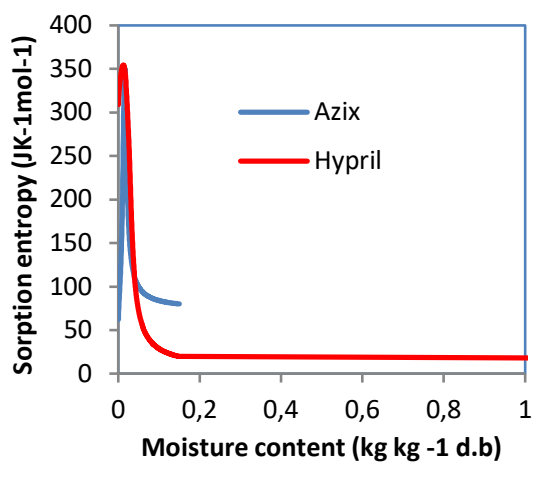

Fig. $2 b$ Sorption entropy of Azix and Hypril formulations

\subsection{Integral enthalpy and entropy}

The variations in net integral enthalpy with the moisture content for Azix and Hypril are shown in Fig. 3. On the whole range of equilibrium moisture content, the integral enthalpy of both products decreases as a function of equilibrium moisture content until reaching minimum values then they remains constant.

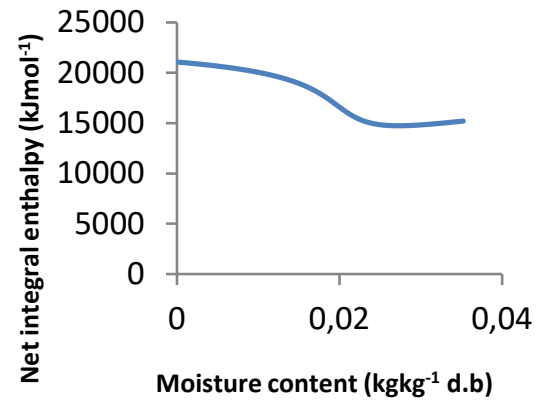

Fig. 3a Net integral enthalpy of Azix formulation

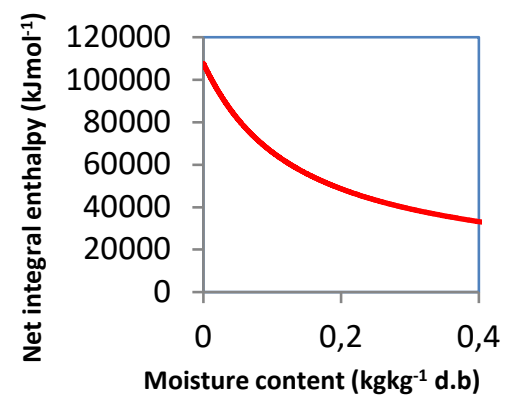

Fig. $3 b$ Net integral enthalpy of Hypril

\section{Formulation}

Variations of the net integral entropy (Fig.4) of Azix and Hypril showed different trends. Values decreased with equilibruim moisture content for Hypril and increased for Azix. The better conditions to assure stability to the powders during storage [7] are those corresponding to lower entropy values. 


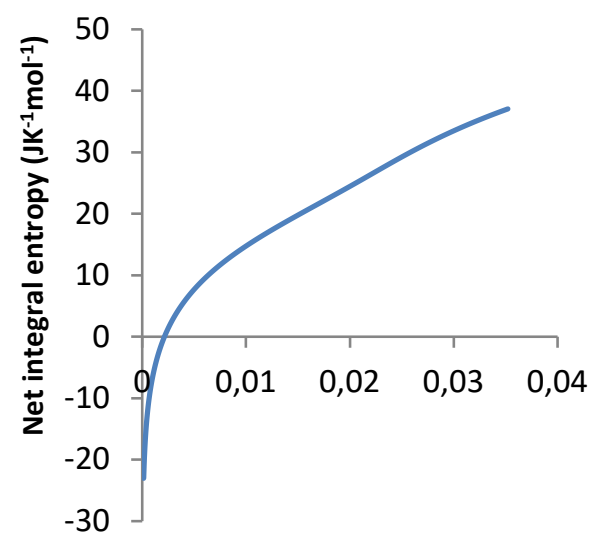

Moisture content $\left(\mathrm{kgkg}^{-1} \mathrm{~d} . \mathrm{b}\right)$

Fig. 4a Net integral entropy of Azix formulation

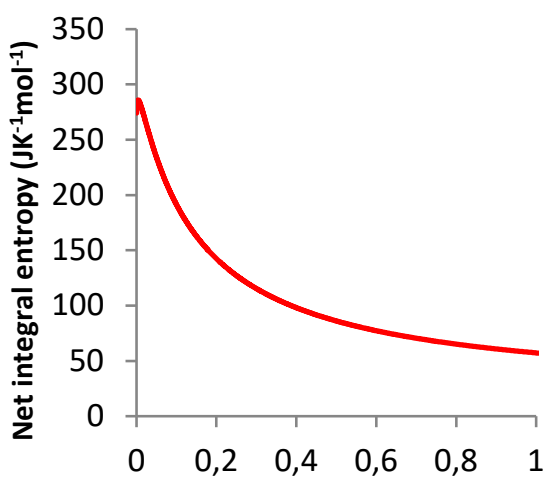

Moisture content $\left(\mathrm{kgkg}^{-1} \mathrm{~d} . \mathrm{b}\right)$

Fig. $4 b$ Net integral entropy of Hypril formulation

\section{Conclusions}

This study affords an understanding of the sorption isotherms and the thermodynamic properties of two powders with different compositions. The obtained results suggest that the two products could be dehydrated at lower temperature $\left(50^{\circ} \mathrm{C}\right)$ since the isotherms of sorption are independent of temperature. Azix preparation seems to be less hygroscopic and more stable than Hypril preparation which requires less energy to be dehydrated.

\section{References}

[1] AOAC AOAC Official method, 1990.

[2] Reddy, T. A. Applied Data Analysis and Modeling for Energy Engineers and Scientists: Springer US, 2011.

[3] Kechaou N. Thesis 'Etude théorique et expérimentale du processus de séchage de produits agroalimentaires', Faculté des Sciences de Tunis, 2000.

[4] Zhou, Q.; Loh, Z. H.,;Yu, J.; Sun, S.-p.; Gengenbach, T., Denman, J. A. How Much Surface Coating of Hydrophobic Azithromycin Is Sufficient to Prevent Moisture-Induced Decrease in Aerosolisation of Hygroscopic Amorphous Colistin Powder. The AAPS Journal. 2016 , 18(5), 1213-1224, doi:10.1208/s12248-016-9934-x.

[5] Al-Omari, M. M.,; Abdelah, M. K.; Badwan, A. A.; Jaber, A. M. Y. Effect of the drug-matrix on the stability of enalapril maleate in tablet formulations. Journal of Pharmaceutical and Biomedical Analysis. 2001, 25(5), 893-902, doi:https://doi.org/10.1016/S0731-7085(01)00399-5.

[6] Bronlund, J.; Paterson, T. Moisture sorption isotherms for crystalline, amorphous and predominantly crystalline lactose powders. International Dairy Journa 1 2004, 14(3), 247-254, doi:https://doi.org/10.1016/S0958-6946(03)00176-6.

[7] Cano-Higuita, D. M.; Villa-Vélez, H. A.; Telis-Romero, J.; Váquiro, H. A.; Telis, V. R. N. Influence of alternative drying aids on water sorption of spray dried mango mix powders: A thermodynamic approach. Food and Bioproducts Processing 2015, 93, 19-28, doi:https://doi.org/10.1016/j.fbp.2013.10.005. 